\title{
Applying the Strategy of Village Revitalization to Manage the Rural Hollowing in Daba Mountains Area of China
}

\author{
Zhang Lijuan ${ }^{1}$, Zhang Guoyi ${ }^{2}$ \\ ${ }^{1}$ Southwestern University, School of Economics and Management, Chongqing, China \\ ${ }^{2}$ Sichuan Administration Institute, Chengdu, Sichuan Province, China \\ Correspondence: Zhang Lijuan, Southwestern University, School of Economics and Management, Chongqing, China.
}

Received: May 28, 2018

doi:10.11114/aef.v5i3.3248
Available online: April 26, 2018

URL: https://doi.org/10.11114/aef.v5i3.3248

\begin{abstract}
In the process of rapid urbanization and industrialization, the "hollowing out" of rural areas in China is getting hotter and hotter. And the situation is grim. The countryside in Daba Mountains Area of China has suffered serious decline. The problem of "hollowing out" has been prominent and is one of the main areas of governance. Therefore, based on the strategy of rural revitalization and based on the status quo of Daba Mountainous Rural Areas, this paper analyzes the causes of the increasing severity of rural" hollows out" and defines the logic and path of governance. Then, promoting the improvement of the hollowing out of rural areas in Daba Mountains Area of China is also the purpose of this paper.
\end{abstract}

Keywords: rural revitalization strategy, rural hollowing, daba mountains area, governance path

\section{Introduction}

In October 2017, China put forward the implementation of the "Strategy of Village Revitalization" for the first time. This is a pertinent strategy based on the status quo of the backwardness of China's rural development. "Strategy of Village Revitalization" aimed at prospering the rural economy. Under the premise of consistently adhering to the priority development of agriculture and rural areas, China's ruling party have made efforts to transform "prosperous industries, livable ecology, rural civilization, effective governance, and a prosperous life" into new labels for beautiful countryside. "Strategy of Village Revitalization" is the result of China's ruling party standing at a new historical height to reexamining the status quo and trends of China's rural development. To implement the "Strategy of Village Revitalization" is also an inevitable requirement for China's rural development had reached a new stage.

The blueprint described in the "Strategy of Village Revitalization" indicates the direction for the development of China's rural economy. Its strategic objectives also inject new vitality into the rural economic workers. However, the reality of the sluggish development of rural areas in China cannot be avoided. Among them, the "hollowing out" of rural areas is the most prominent performance. Looking at the statistics, we can see that in China's 655 cities, 640,000 administrative villages, and more than 3 million natural villages, more than $50 \%$ of them have experienced severe" hollow out". There is a lot of literature on "hollow out" of Chinese villages. (Chen and Liu, 2012) believe that rural "hollow out" is the overall situation and true portrayal of rural decline in China's modernization process. It is necessary to achieve the goal of filling rural hollowness through policy innovations in various aspects such as agricultural production and rural social culture. (Wang, Liu, 2013) conducted a quantitative analysis of the data obtained from the "hollowing out" of rural in Shandong Provence and concluded that the development of the development plan will enhance the village's elemental cohesion. On this basis, identifying the dominant factors of rural hollowing and dividing different types of rural hollow areas to formulate differentiated prevention and control countermeasures. (Wa, 2017) proposed to strengthen the village "two committees" from the perspective of precision poverty alleviation and provide organizational guarantees for the "hollow out" villages to lift themselves out of poverty; Developing new modernized agriculture industry, encouraging the participation of rural social organizations and increasing the economic efficiency and improving self-government capacity of leftover villagers to solve the "hollow out" villages problem. Rural "hollowing" has already constrained the pace of China's rural development (Lin, 2005). And it needs to stand in the perspective of a new era to analyze real problems. In the context of the "Strategy of Village Revitalization", the review of the "hollowing out" of rural villages and targeting the problem to governance have become the development 
direction of rural development in China. It is also due to the "Strategy of Village Revitalization" Taking the Daba Mountains Area at the junction of the four provinces (cities) of Chongqing, Sichuan, Shaanxi, and Hubei in China as an example, this paper explores the path to govern "hollowing out" rural areas of Daba Mountains Area ${ }^{1}$ in the context of "Strategy of Village Revitalization". It is hoped that the framework for solving the problem of "hollowing out" in the governance of Daba Mountains Area will be theoretically established. This is also the purpose and significance of this paper.

\section{Research Methods}

In this paper, a combination of qualitative and quantitative research, literature research and field surveys is used for research.

Qualitative research mostly uses participation observation and in-depth interviews to obtain first-hand data. Specific methods include participation in observation, action research, historical research methods, and ethnographic methods. Among them, participation in observation is a method often used in qualitative research. The advantage of participating in observation is that it not only observes the reasons, attitudes, efforts, and decision-making of actions taken by the observer. By participating, researchers can gain a sense of a member of a particular social context and thus be able to understand actions more fully. Then, through the observation and interviewing methods, the induction method was used to gradually transform from the concrete to the abstract and form the theory. Qualitative research is based on "founded theory." The theory formed by this method is generated from the interconnection of many different types of evidence collected. This is a bottom-up process.

Quantitative studies are generally conducted to obtain statistical results for the population of a particular subject. In quantitative research, information is represented by some kind of number. In the processing and analysis of these figures, it is necessary to determine the measurement and processing of these information based on what scale.

The literature research method mainly refers to collecting, identifying, and collating documents and forms a scientific understanding of facts through the study of documents. The literature method is an ancient, yet vigorous, scientific research method.

The field investigation is under a well-organized structure and the investigators collect the first-hand information from the interviewees directly. First-hand data, also known as primary data, refers to data collected for the first time. The investigators use the eyes to collect information by directly observing specific items.

\section{The Logical Mechanism and Key Influencing Factors of Rural Hollowing}

In the late 1970s, with the opening of reform and opening up in China, the rural labor force changed quietly. The released labor force generally works in cities in China along the eastern coast. With the continuous evolution of this process, the rural areas in China have begun to appear "hollow out" by the old and young. Although the hollowing out of rural areas is related to the China's development environment, the gradual shrinkage of rural areas has its own inherent logic and key influence factors. The logical starting point for the governance of rural hollowing is to clarify the key elements of the formation of hollowing out and the logical relationship between the elements.

\subsection{The Appearance Phenomenon of Rural Hollowing Is that Rural Areas Are Gradually Losing Their Attraction to Human Capital}

In order to seek a better life, rural laborers in China have rushed to the cities. The loss of rural human capital is mainly manifested as dominant loss and invisible loss. The dominant loss mainly includes the loss of outstanding young adults. The invisible loss is reflected in the decline of the health status of rural surplus population and the decline of the labor force. Specifically, it can be seen from two aspects: First, there is a significant loss from the quantity collected. In the period of 2011-2016, the number of migrant workers nationwide continued to increase, with growth rates of 3.4\%, 3\%, $1.7 \%, 1.3 \%, 0.4 \%$, and $0.3 \%$ respectively. The proportion of migrant workers out of the total migrant workers also gradually changed from $62.8 \%$ in 2011 to $60.1 \%{ }^{2}$ in 2016. Despite the slowdown in growth rate and the decrease in the proportion. The number of migrant workers in China, mostly young and middle-aged, has continued to flood into the economically prosperous developed regions. The number of migrant workers continues to rise, and the "hollow out" of rural areas continues to grow. This phenomenon will inevitably lead to the rural areas leaving only elderly people and children with low labor capacity.

\footnotetext{
${ }^{1}$ The Daba Mountains Area studied in this paper is based on Ningqiang County, Zhenba County, Zhenping County, Nanjiang County, Wanyuan City, Wangcang County, Chengkou County, Wushan County, Wuxi County, Shennongjia, Badong County in China, etc. 11 counties are bounded.

${ }^{2}$ Source of data: National Bureau of Statistics: "National Monitoring Report on Migrant Workers in 2016"
} 
3.2 The Deep-Seated Reason for the Hollowing out of Rural Areas Is the Lack of Humanistic Desert and Rural Cultural Construction

Field surveys found that when ranking five levels of attention in China's new rural construction: "producing development, a comfortable life, rural civilization, clean and tidy village, and democratic management", only 26 of the 480 farmers interviewed said that The most concerned about rural civilization, only $5.6 \%$ of the total sample. This situation is a concentrated reflection of spiritual life in rural China. With the loss of a large number of village labor forces, under the influence of the trend of urbanization in the rural areas of China, the local moral and cultural order is in the process of disintegration. However, the new moral cultural forms have not yet been fully stereotyped. Besides, moral and cultural desertification has occurred, which has also made low quality human resources destroys the social atmosphere in rural areas. On the one hand, young adults are the learners who have concentrated on the humanistic spirit and culture. As they have left the countryside for a long time and are not living in rural areas, what remains in the countryside is only the phenomenon of the decline of spiritual civilization. In addition, because the cultural level of the remaining population is not high, peasants are prone to irreconcilable conflicts due to small frictions. On the other hand, due to the relatively weak economic foundation in China's rural areas, investment in rural culture is generally low. With the acceleration of urbanization, the outflow of young adults has led to the outflow of other resources, making the main body of rural cultural construction vacant. Villagers have few opportunities to participate in cultural activities. And rural cultural construction has been further suspended. The slow construction of rural culture has further widened the gap with progressive urban civilization. This widening gap has also contributed to the further deterioration of rural hollowing.

\subsection{The Secondary Causes of Hollowing in Rural Areas Are Organizational Fragmentation and Rural Governance}

As the hollowing out of rural areas continues to evolve, many rural areas in China have become increasingly ineffective due to organizational fragmentation. Mainly manifested as the following aspects: First, excellent human resources cannot be maintained. College students are more difficult to introduce village officials. Compared with cities and towns, the rural economy and backward transportation have caused the outflow of outstanding human capital and impeded the introduction of college students' village officials. Second, the participation of social organizations is low. The governance of hollowing out of the countryside requires not only government participation but also support from social organizations. For nearby social organizations, due to the fact that they are mostly small-scale organizations, their strength is not strong, their ability to take up social responsibility is low and their participation in rural governance is beyond their control. So participation is low. For the more far and powerful social organizations, because the rural grass-roots organizations in the mountains insufficiently call for social organizations. Information on social organizations and rural conditions is asymmetric, which also reduces the participation of social organizations. Third, clan forces and village tyrants erode grassroots organization authority. China's backward rural areas, especially ethnic areas, are also vulnerable to traditional concepts, such as "family ideology". They are vulnerable to the status quo, lack the spirit and spirit of pioneering and enterprising and family govern the home and village. To a certain degree, these weakens are impair the cohesiveness and authority of grass-roots ruling party organizations. Fourth, the organizational construction of the ruling party needs to be further strengthened. China's grass-roots ruling party organization has a single phenomenon such as the organization and living forms. And the ruling party's organizational cohesion is not strong enough.

\subsection{The Direct Cause of Rural Hollowing Is the Lack of Industrial Hollowness and Rural Economic Development}

Due to the fact that the rural areas in China's rural areas are scattered throughout and the villages have a large distribution area, the construction of water、 road and electricity infrastructure is hindered. In addition, rural human capital flows to cities in one direction, and rural areas lose their popularity. The incomplete infrastructure and the loss of skilled personnel have made it difficult for the various industries in the countryside that can drive the local economy to take root. At the same time, agriculture, especially planting, is difficult to scale up. Rural resources have not been used and are idle. This is a huge loss. The hollow of the industry has caused the development of the rural industry to be weak. And the rural economy has failed to achieve "hematopoietic" development.

\subsection{The Crux of the Hollowing out of Rural Areas Is the Idleness of Resources and the Depressed Market of Rural Factors}

The massive loss of labor force and the lack of economic development plans have made the shelving of rural factor assets more serious. As far as natural resources are concerned, most rural areas in China have better land and water resources and biological resources, especially in the rural areas where a lots of trees are located. However, due to the remoteness of rural areas, the obstruction of roads, water conservancy and other infrastructures, natural resources are difficult to export. As far as housing resources are concerned, the phenomenon of expanding space outside but hollowed inside in China is outstanding. According to statistics, the number of permanent residents in rural areas in China is decreasing at a rate of $1.6 \%$ each year. However, homesteads increase at a rate of $1 \%$ per year. Rural houses are built 
every year. It covers an area of about 2 million mu( $1 \mathrm{mu}$ is $666.67 \mathrm{~m} 2)$; in the 13 years from 1996 to 2009 , the total land for urban and rural construction increased by 38,000 square kilometers, an increase of $13.33 \%$.The total area of cultivated land during 1996-2011 was reduced by 124 million mu, a decrease of 6.4\%. Some scholars surveyed in 2013 found that the average hollowing rate of Chinese village homesteads was $10.15 \%$. From the spatial point of view, the hollowing rate of village homesteads in mountainous areas (12.24\%) was higher than that of the plain areas (9.91\%) and the hilly area (5.86\%).It followed by a large number of abandoned houses; as far as cultivated land resources are concerned, due to the long-term output of the labor force, rural farmland is seriously abandoned, and wasteland is fragmented.

\section{Status Quo of Rural Hollowing in Daba Mountains Area}

Daba Mountains Area is a collective name for the borders of the four provinces (cities) in China of Chongqing, Sichuan, Shaanxi, and Hubei. It is also a gathering place for the old revolutionary base area. Its mountainous structures are closely folded and faults are developed. And there are numerous mountains and river valleys. There are a total of 1,700 administrative villages in the mountainous area, with a rural population of 2.7 million, accounting for $61.21 \%$ of the total population. Among them, the rural permanent population accounts for only $46.77 \%$ of the total rural population. And the rural population is hollow. According to the data from the National Bureau of Statistics, the per capita disposable income of rural residents in 2015 was 11,422 Yuan, while 8746 Yuan in Daba Mountains Area, which was far below the national level. The rural population's low income is one of the major cases of human capital out flow. The low income of the rural areas, the lack of manpower, and the spiritual emptiness, idle resources, and hollowed out industries in Daba has made the overall economy of rural been lagging backward long-term. Daba Mountains Areas one of the major regions that govern rural hollowing.

\subsection{Manpower Shortage, Low Human Capital in Rural Areas}

According to the field investigation, among 7 towns, 58 administrative villages and 39,000 households in Zhenping County, 9715 households with permanent residence have been relocated permanently, accounting for $25 \%$, among which there are 783 fixed residences and 770 rental housing units outside the province. There are 584 permanent residences in the province, 461 rental houses, and 5,420 permanent residences and 1,697 rental housing. The county did not relocate 29,285 households, accounting for $75 \%$ of the households, leaving 5,027 of the elderly to stay, accounting for $17.2 \%$. In Zhenping County, the urbanization rate reached 39\% in 2016. The proportion of rural real life population accounts for nearly $50 \%$ of the total rural population. The proportion of rural young people under the age of 50 who have long-term migrant work is close to $80 \%$. The spillover effects of the resources generated by the migration have hampered the development of rural economy in the county. The hollowing out of human resources makes the construction and development of new rural infrastructure public welfare undertakings lack of strength. A large number of young and middle-aged labor forces have gathered in cities and labor service bases, resulting in a low level of rural population quality and weak rural construction. A large number of high-quality peasants have been lost. Most of the ordinary peasants left behind are old and sick, women and children.

\subsection{Spiritual Desert, Weak Rural Cultural Construction}

The rural of Daba Mountains Area should integrate red culture and green culture. The rural of Daba Mountains Area has undergone a history of precipitation and has a farming culture with local characteristics. In addition, it is also one of the bases for the second period of the Revolutionary Civil War in China. Therefore, according to common sense, Daba Mountains Area should be a region with deep cultural heritage. However, due to the influence of modern trends, the loss of excellent human capital, coupled with the lack of cultural infrastructure, has led to a fault in cultural transmission and has continued to deteriorate. The awareness and protection of the red cultural heritage in the mountainous areas are low. On the other hand, the traditional fine moral culture is being eroded. The specific manifestation is that some red cultural relics or sites in the mountainous areas are not respected or even destroyed by the rural areas, the cultural infrastructure of the village is seriously deficient, and the peasants' cultural taste is low. And cultural activities are almost absent. Farmers often have conflicts due to small interests. Even if there is a certain development in rural areas, the construction of heavy material civilization and the construction of light spiritual civilization are relatively prominent. Some local leaders have focused on the construction of hardware facilities such as "building houses and repairing roads" and neglected the construction of spiritual civilization in rural areas. The lack and backwardness of rural cultural facilities in Daba Mountains Area and the deterioration of the village style has exacerbated the peasants' tediousness towards the country and the rejection of traditional farming life.

\subsection{The Organization Is Fragmented and the Rural Governance Operation Is Inefficient}

The rural of Daba Mountains Area is mostly in the mountains and there are fewer information about outside than in the plains. Therefore, social governance in rural areas is inefficient and economic development has stalled or slowed. As far as village tyrants and clan phenomena are concerned, due to backward economic development and lower education 
levels in some mountainous rural, many school-age children have no books to read and are unemployed. As a result, they fall into the "village tyrants" and oppress the villagers. Erosion of the grassroots regime. In addition, due to the large number of ethnic minorities in Daba Mountains Area and their complex religious beliefs, there are clan manipulation powers in some places, which hinder rural social governance. As far as grass-roots organizations are concerned, the aging of grass-roots ruling party members is more serious than that of rural areas in other regions. Their physical fitness is low and their ability to learn is not strong. Due to lack of new knowledge and new ideas, the cohesiveness of grass-roots organizations is not high enough so that they can not better organize and better lead the villagers to develop their wealth. Looking at the actual situation of many rural villages in the mountainous areas, the concrete manifestations are as follows: First, the infrastructure of the activities is not perfect. There is insufficient or even lack of organization of the public affairs propaganda party. And there is a lack of organizational activities. Second, the organizational system is not perfect. Such as the development of the members of the ruling party, the lack of appropriate system construction and supervision, the actual operation process can not strictly follow the procedures, and more obscure operations, resulting in most of the villagers do not understand the development policy of the ruling party members.

\subsection{Hollow Industry, Insufficient Rural Economic Development}

In the 1700 administrative villages covered by this paper, according to sample surveys, the number of villages with rural collective economies accounts for less than 50\%, the proportion of villages with family farms is less than $30 \%$, and the number of villages with business-related township enterprises less than $40 \%$. Because of the poor geographical conditions in Daba Mountains Area, the village's basic infrastructure construction line is too long, which increases the difficulty of building infrastructure such as rural water, electricity, roads, and telecommunications. Therefore, it is difficult for external resources to flow in and restrict the development of the rural economy. The mountainous area has a thin foundation, lack of funds, backward technology, poor production conditions, combined with the loss of excellent human capital, difficulty in seeing large-scale operations, and serious industrial hollowness. However, Daba Mountains Area has the abundant resources for industrial development and the physical conditions for adjusting the industrial structure. The potential for economic development in the mountains is huge and the future is bright. As long as this advantage is exerted, the mountainous economy will surely come from behind.

\section{Analysis of the Path of Hollowing Governance in Rural Areas of Daba Mountains Area}

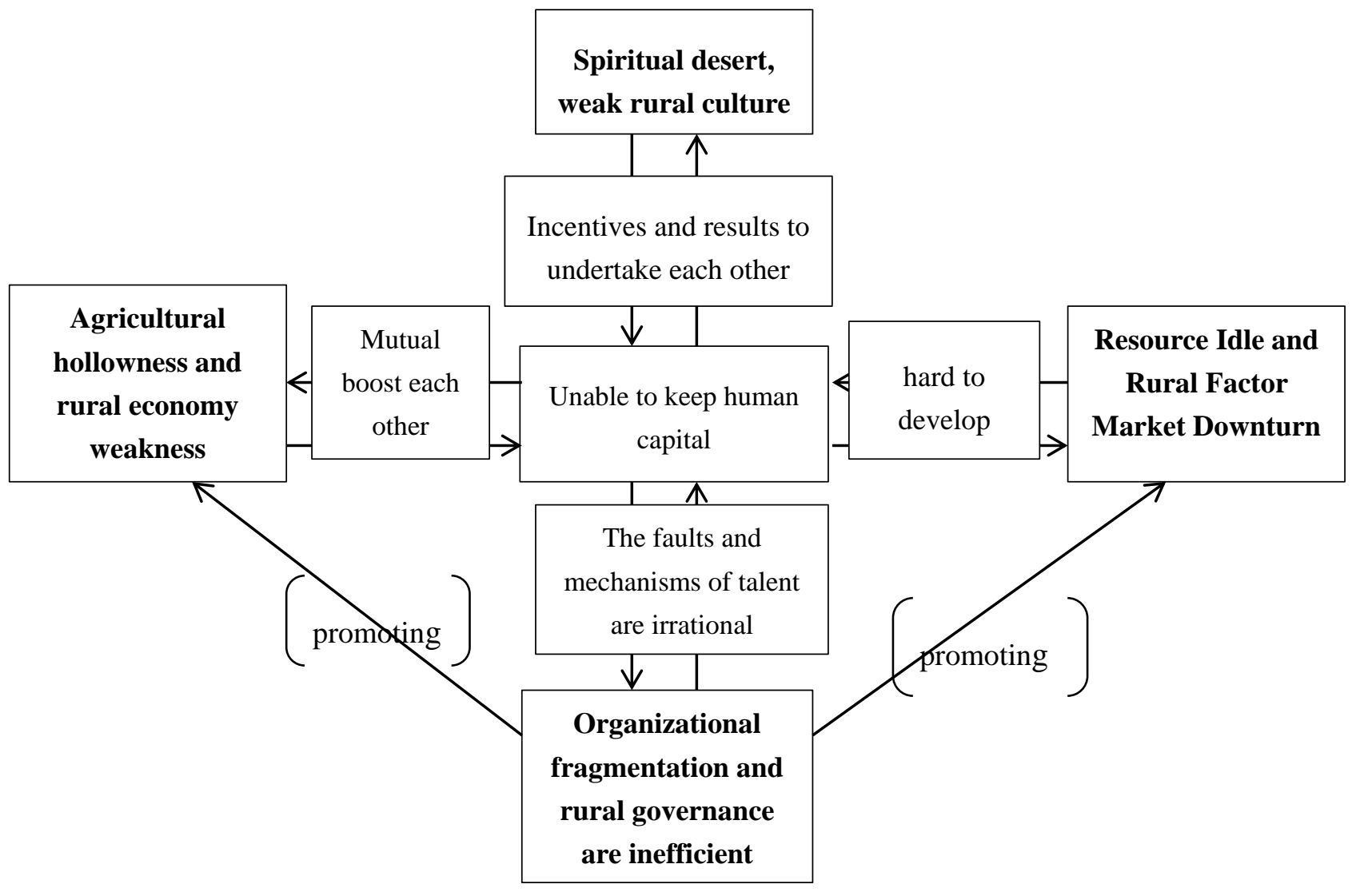

Figure 1. Rural Hollowing Logic Analysis Figure 


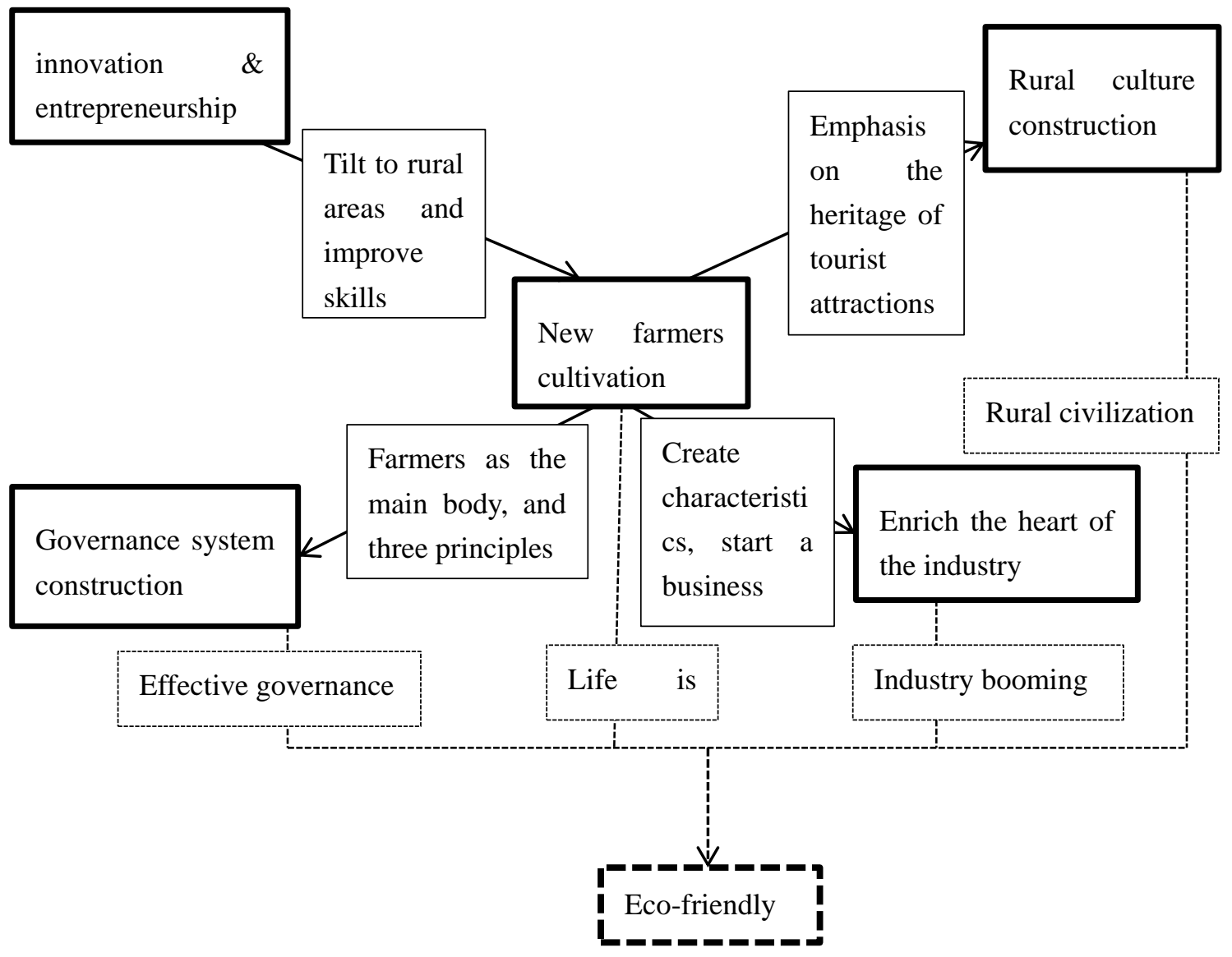

Figure 2. The Logical Governance Figure of Rural Hollowing in Daba Mountains Area

\subsection{Based on the Opportunity of Innovation and Entrepreneurship Policy to Promote the Cultivation of New Types of Rural Work for the Region}

In the era of popular entrepreneurship and innovation, various aspects of innovation and entrepreneurship policies have been continuously introduced. For example, on November 29, 2016, the General Office of the State Council of the People's Republic of China printed and issued the "Opinions on Supporting the Entrepreneurial Innovation of Returned Rural People to Promote the Integrated Development of the Secondary and Secondary Three Industries in Rural Areas", clearly defining the peasant workers, graduates of secondary and tertiary institutions, and retired soldiers who start entrepreneurs has kinds of resource to support. Despite the disadvantages of roads and funds, rural of Daba Mountains Area have the advantages of ecological environment and factor endowments. It needs excellent human resources to return to tap the mountain potential to rejuvenate the countryside. Therefore, the management of "hollowed out" can actively seize this opportunity, set off a wave of local farmers' innovation and entrepreneurship to make the average profitability of the income of all new agricultural-industry industries catch up with the urban level.

\subsection{Based on the Basic Idea of Cultural Self-Confidence, Promote the Construction of Regional Excellent Farming Culture}

The rural landscape of Daba Mountains Area and the country's native culture are rich and varied. There are also sites of local red cultural relics. The farming culture originated in the farmers' long-term production and life, which contains many excellent moral and cultural qualities. It has a natural appeal to the farmers. Based on cultural self-confidence, the best way to inherit and promote excellent farming culture and red culture is to develop it into a cultural tourist attraction. On the one hand, this has led to the construction of cultural infrastructure in rural areas and continued protection of the two cultures. On the other hand, advanced knowledge education and management methods have been brought in, which make the villagers to live in harmony and understand each other.

To develop a variety of tourism forms centered on farming culture, the government needs to analyze and predict rural tourism to ensure the sustainable development of rural tourism. On the other hand, according to the actual conditions of each district, propaganda and education are carried out in a way that the farmers like to see, so that these outstanding 
moral traditions and values are internalized into the farmers' moral values. The field investigation revealed that Nanjiang County in China had succeeded in this aspect. In 2016, Nanjiang County received 5.189 million tourists from rural tourism, and realized rural tourism income of 4.22 billion Yuan, an increase of $36.7 \%$ and $37.4 \%$ year-on-year respectively. In the first quarter of 2017, the county's rural tourism received 1.223 million tourists, realizing rural tourism income of 8.395 billion Yuan, a year-on-year increase of $23 \%$ and $20.9 \%$ respectively.Through scenic spots, making full use of farming culture to the farmers' natural feelings of intimacy to awaken farmers' love for their homeland and to promote the construction of rural civilization and to provide spiritual support for the construction of new countryside.

\subsection{Based on the Rule of Law of Self-Government and Rule of Law, Improve the Rural Social Governance System in the Region}

The rural grass-roots organizations in Wabasha's Area are fragmented and social governance has had little effect. The main reason is that there is no "three governance" governance framework. China's "strengthening rural basic-level basic work and strengthening the village governance system that combines self-government, rule of law, and rule by virtue" proposed in October 2017 has pointed out a new direction for future rural governance. Social governance in rural areas is the most basic, critical, and most difficult area of social governance. In order to make governance effective, it is necessary to cultivate the sense of ownership of the villagers and try the rule of the villagers and autonomy. As far as the rural of Daba Mountains Area is concerned, there are many such autonomy. Many villagers do not know how to use legal weapons to safeguard their legitimate rights and interests, and small disputes have frequently intensified into large cases. Therefore the rule of law is essential. At the beginning of 2017, the Supreme People's Procurator ate of China has issued the "Opinions on Fully Exerting the Procurator ate Function to punish "Village Overlords" and Clan Forces for Evil Forces and Actively Maintain Harmonious and Stable Rural Areas", highlighting the crackdown on acting as an "umbrella" for the "village tyrants" and clan evil forces, which have brought the Gospel to rural social governance in Daba Mountains Area. Grassroots organizations need to do a good job of legal advocacy. The government should strive to introduce fresh blood to grass-roots organizations and through clarification of organizational functions to improve organizational structure and enrich management tools, which will form a multi-dimensional governance structure in which the grass-roots ruling party organization is at the core and the society participates in multiple parties.

\subsection{Based on the Concept of Urban-Rural Integration Development, Promote the Development of Resource Elements Industrialization}

Daba Mountains Area has rich animal and plant resources, rich mineral resources, fertile soil and a suitable climate. In addition, the realization of industrialization in resource-rich areas is the key to solving the downturn in mountainous factor markets. Therefore, in the rural of Daba Mountains Area, new professional farmers should be the mainstay and introducing advanced production technologies and concepts to establish various industrial bases such as ecology and tourism agriculture, tourism, and industry (mining). If Daba mountains Area achieves an effect on the industrial base, the productivity level, commodity production level and economic level of Daba Mountains Area will be greatly improved. And the economy of mountainous areas will surely take off. Therefore, Daba Mountains Area can certainly be constructed well. At that time, Taka Yama Mountain can also become mountains of gold and silver. The resource element can achieve great development and flow between urban and rural areas.

First of all, it is necessary to develop production and management of agricultural products that have their own regional advantages to cultivate the industrialization chain of agriculture. Secondly, it should also develop agricultural cooperation and economic organizations, foster rural industrialization carriers, cultivate leading enterprises, and influence rural industrialization operations. Finally, for the important resource of land, the first is to achieve land circulation and intensive use. It lays the foundation for the industrialization of rural areas. The rural land system is the first element that determines rural development. Therefore, the reform of the rural property rights system in Daba Mountains Area is to ensure the registration of the right to obtain certification. Rural areas can implement correct and inaccurate practices in the collective economy. With land shares, the scattered land will be gathered to achieve large-scale operations. The second is to build a platform. Through actively setting up and putting into operation the rural property rights trading platforms throughout the Daba Mountains Area. If the institutional platform for the transformation of social capital into rural and rural resources to capital has been established, the foundation for opening channels for free flow of urban and rural production factors will be settled up. The third is to establish an effective market orientation and multiple participation mechanisms and improve the compensation mechanism for property rights circulation. This will surely revitalize rural resources that have been quiet for many years, making rural ecology loveable and industries prosperous.

\section{Conclusions}

In the process of urbanization, it is normal for some rural areas to disappear. But the prosperity of the city is accompanied by the general decline of the rural areas as a manifestation of the unbalanced social development. The 
"strategy of rejuvenating villages" in the new era has achieved two-way flow between rural areas and urban in Daba Mountains Area. It has given clear direction to the effective governance of rural hollowing and is conducive to improving the status quo of rural "hollowed out". However, the governance of rural "hollowed out" still needs to return to the development of the industry based on new farmers. Let the development of the industry fill the hollowed-out countryside instead of relying solely on the "blood" of the national policy to enable it to achieve its own "blood-making" function. Taking the Daba Mountains Area as an example, this paper explores the ways to manage the hollowing out of rural areas in Daba Mountain. However, China's rural realities vary widely. Other forms of governance for contiguous rural areas have both commonalities and individualities. What they have in common is that they are in the process of China's reform and opening up. The causes of "hollowed out" are similar; the difference is that in order to manage hollow villages, it is necessary to determine the industries that drive economic development based on local resources. It requires detailed analysis of specific issues and cannot blindly copy successful cases.

\section{Fund}

2017 National Social Science Foundation Youth Project of China (2017CJY030), 2016 Sichuan Province Social Science Planning General Project (SC16B060); The Key Project of National Party School System in 2017, Research on the Optimization of the Distribution Mechanism of Farmers, Managers, and Collectors of Land under the Background of "Three-Power Distribution"; Sichuan Provincial Soft Science Project (2018ZR0079) "Optimization of Interactive Mechanism of Rural Land, Population and Industry in Sichuan Province under the Background of Hollowing of Natural Villages".

\section{References}

An, M., \& Liu, D. (2017). Governance of Rural Hollowing in Poor Regions Based on Ethical Analysis. Journal of Shangluo University, 31(03), 88-92.

Huang, K. (2018). Research on Governance of Hollowing in Rural Areas: A Review Perspective. Journal of Agricultural Economics, (01), 47-49.

Le, B. (2018). Governance of Rural Hollowing under the Background of Rural Construction: Based on Field Survey in Nanjing City. Journal of Anhui Agricultural Sciences, 46(02), 201-209.

Lin, Y. (2005). Institutions, Technology and Agricultural Development in China. Shanghai, Shanghai People's Publishing House.

Liu, Y. (2011). Scientifically promoting China's rural land remediation strategy. China Land Science, 25(4), 3-8.

Liu, Y. (2017). Governance Strategy of Rural Hollowing under the Perspective of Urban-rural Integration. Higher Agricultural Education, 2017(02), 118-123.

Lu, S. (2012). Enlightenment on the Philosophy of Culture. Philosophical Developments, (1), 20-21.

Sheng, Y. (2012). Enthusiastically building the old revolutionary base areas in Daba Mountains Area. Philosophical Developments, (1), 20-21.

Tian, X. (2017). Governance of Rural Tourism Development and Hollowing in Rural Areas. Agricultural Economy, (04), 52-54.

Wang, W. (2013). China's land management system: status quo, problems and reforms. Journal of Nanjing Agricultural University (Social Science Edition), 13(4), 76-82.

$\mathrm{Xu}, \mathrm{Y}$. (2014). Cross-border crossing: promoting social governance in joint creation. Beijing, China Social Sciences Press, 3.

Ye, J. (2006). New rural construction from the perspective of farmers. Beijing, Social Sciences Academic Press, 100.

\section{Copyrights}

Copyright for this article is retained by the author(s), with first publication rights granted to the journal.

This is an open-access article distributed under the terms and conditions of the Creative Commons Attribution license which permits unrestricted use, distribution, and reproduction in any medium, provided the original work is properly cited. 